\title{
Presentación diferencial de ARN mensajeros e identificación del gen selenocisteína liasa en células de carcinoma hepatocelular con expresión transitoria de la proteína core del virus de la hepatitis C
}

\author{
Jesús Orlando Yepes ${ }^{1}$, María Luz Gunturíz ${ }^{2}$, Luis Felipe Henao ${ }^{1}$, María Cristina Navas ${ }^{1}$, \\ Norman Balcázar ${ }^{3}$, Luis Alberto Gómez ${ }^{2,4}$ \\ ${ }^{1}$ Grupo de Gastrohepatología, Facultad de Medicina, Universidad de Antioquia, Medellín, Colombia. \\ ${ }^{2}$ Grupo de Fisiología Molecular, Instituto Nacional de Salud, Bogotá, D.C. Colombia. \\ ${ }^{3}$ Grupo de Inmunovirología, Universidad de Antioquia, Medellín, Colombia.
}

Introducción. El virus de la hepatitis C se asocia a diversas hepatopatías como hepatitis aguda, hepatitis crónica, esteatosis, cirrosis y carcinoma hepatocelular. Numerosos estudios han explorado mecanismos virales implicados en el establecimiento de la infección persistente y en las propiedades oncogénicas e inmunomoduladoras de la proteína core del virus de la hepatitis C. Las investigaciones orientadas a evaluar los cambios en la expresión de genes celulares endógenos inducidos por la proteína core son importantes para identificar genes candidatos responsables de los mecanismos de patogenicidad del virus de la hepatitis C.

Objetivos. Comparar perfiles de expresión e identificar genes celulares endógenos en la línea celular derivada de carcinoma hepatocelular humano, HepG2, con expresión transitoria de la proteína core del virus de la hepatitis $C$.

Materiales y métodos. Se utilizó la técnica de presentación diferencial de ARN mensajero por RT-PCR en células HepG2 con y sin expresión transitoria de la proteína core del virus de la hepatitis $C$ o de la proteína verde fluorescente, obtenidas previamente con el sistema de expresión del Semliki Forest Virus, mediante transducción de partículas recombinantes rSFVCore o rSFV-GFP.

Resultados. Se observaron diferencias en las intensidades de las bandas de ARNm expresadas en células HepG2 transducidas con rSFV-Core comparadas con células sin transducir y trasducidas con rSFV-GFP. Un ARNm de 258 pb expresado diferencialmente en células HepG2 transducidas con rSFV-Core fue clonado e identificado como selenocisteína liasa.

Conclusión. Los resultados confirman que la expresión de la proteína core del virus de la hepatitis $\mathrm{C}$ se asocia con cambios en la expresión de ARN mensajeros específicos, incluido al gen selenocisteina liasa, el cual puede estar involucrado en la fisiopatología del carcinoma hepatocelular.

Palabras clave: hepatitis $\mathrm{C}$, expresión génica, carcinoma hepatocelular, ARN mensajero, virus ARN, selenocisteína.

Differential display of messenger RNA and identification of selenocysteine lyase gene in hepatocellular carcinoma cells transiently expressing hepatitis $\mathbf{C}$ virus Core protein

Introduction. Hepatitis C virus is associated with diverse liver diseases including acute and chronic hepatitis, steatosis, cirrhosis and hepatocellular carcinoma. Several studies have explored viral mechanisms involved in the establishment of persistent infection and oncogenic Hepatitis $C$ virus. Expression assays of Hepatitis $C$ virus core protein suggest that this protein has transforming and carcinogenic properties with multifunctional activities in host cells. Characterization of expressed genes in cells expressing Core protein is important in order to identify candidate genes responsible for these pathogenic alterations.

Objective. To compare and identify gene expression profiles in the human hepatocarcinoma derived cell line, HepG2, with transient expression of Hepatitis C virus Core protein. 
Materials and methods. We have used comparative PCR-mediated differential display of mRNA from HepG2 hepatocarcinoma with and without transient expression of HCV Core protein or green fluorescent protein, previously obtained using the Semliki Forest Virus-based expression, through transduction of recombinant particles, rSFV-Core and rSFV-GFP, respectively.

Results. We observed differences in band intensities of mRNA in HepG2 cells transduced with rSFV-Core compared with those detected in cells without transduction, and transduced with rSFV-GFP. Cloning and sequencing of a gene fragment (258 bp) that was expressed differentially in HepG2 cells transduced with rSFV-Core, was identified as selenocystein lyase.

Conclusion. The results confirm that HCV Core protein expressed in HepG2 is associated with specific changes in mRNA expression, including the gene for selenocystein lyase. This gene may be involved in the pathophysiology of hepatocellular carcinoma.

Keywords: hepatitis C; gene expression; carcinoma, hepatocellular; RNA, messenger; RNA viruses, selenocisteine.

La infección por el virus de la hepatitis $\mathrm{C}(\mathrm{VHC})$, es la causa mas común de hepatitis no $A$ no $B$, postransfusional, y es el principal agente causante de hepatitis crónica, cirrosis y carcinoma hepatocelular (HCC) en el hemisferio occidental $(1,2)$. La Organización Mundial de la Salud estima aproximadamente 170 millones de personas con infección por el VHC a nivel mundial (3). De 50 a $80 \%$ de todas las personas infectadas evoluciona a infección persistente crónica, y de ese porcentaje, $20 \%$ desarrolla cirrosis, condición que predispone al desarrollo de HCC en 1 a $4 \%$ de los casos por año (2).

EI VHC está clasificado en la familia Flaviviridae, género Hepacivirus. El genoma viral corresponde a un ARN de cadena sencilla, de sentido positivo, que codifica una poliproteína procesada por proteasas virales y celulares para dar origen a cuatro proteínas estructurales (core, E1, E2, p7) y seis proteínas no estructurales (NS2, NS3, NS4A, NS4B, NS5A, NS5B) (4-7).

Diversos estudios sugieren que la proteína core, además de ser la unidad estructural de la cápside viral, estaría implicada en las estrategias virales de persistencia y oncogenicidad. Core es una proteína multifuncional de $23 \mathrm{kDa}$ que es

Correspondencia:

Luis Alberto Gómez, Grupo de Fisiología Molecular, Instituto Nacional de Salud, Bogotá, D.C. Colombia. Apartado aéreo 80080. Av Calle 26 No. 51-60. Tel. 57-1- 2207700 ext. 414, fax. 571-2200901.

Igomez@ins.gov.co

Recibido: 27/09/05; aceptado:14/03/06 hidrolizada por una proteasa celular para generar la isoforma p21 (173-179 aa), considerada como la proteína core madura.

El estudio de la secuencia core, que se caracteriza por ser altamente conservada entre los diferentes genotipos, ha permitido identificar dominios implicados en su localización nuclear, en su capacidad de interacción con proteínas involucradas en la regulación transcripcional (810) y la apoptosis (11-13), en su potencial oncogénico (14-16), su capacidad para modificar el metabolismo de lípidos $(17,18)$ y sus propiedades inmunomoduladoras (19-21). Aunque los mecanismos moleculares por lo cuales la proteína core contribuye a la carcinogénesis en hepatocitos no se conoce, se ha sugerido que en esta acción están involucradas alteraciones como la insensibilidad a la inhibición del crecimiento, la evasión de la apoptosis, la inmortalización, la angiogénesis y la metástasis (11-16).

Las evidencias de la capacidad de la proteína core del VHC de modificar procesos celulares se han obtenido a partir de diversas aproximaciones, como la expresión transitoria o estable de la core en líneas celulares y el desarrollo de animales transgénicos para la proteína core. Las evidencias de la modulación de la expresión de genes como c-myc, c-fos, p53, p73 y p21 wat $(8,9,22)$ por acción de la proteína viral core se han obtenido mediante transfección transitoria de construcciones con genes reporteros que contienen las regiones reguladoras de dichos genes; sin embargo, los estudios que buscan evaluar directamente los cambios en la expresión de genes celulares 
endógenos asociados con la expresión de la proteína core del VHC han sido relativamente escasos (23-25).

Una de las razones del poco conocimiento de la expresión génica de células hepáticas infectadas se debe en parte a las dificultades para obtener un modelo eficiente de replicación del $\mathrm{VHC}$ in vitro $(26,27)$; para resolver esta dificultad se han utilizado vectores virales, como el sistema de expresión basado en el replicón de Semliki Forest Virus (SFV), el cual es uno de los más versátiles y eficientes para la expresión de proteínas heterólogas en diversas líneas celulares (28). La eficiencia de este vector en la línea celular HepG2 se ha evaluado para la proteína de cápside del virus de la hepatitis E (29), la proteína core del VHC y la proteína reportera GFP (del inglés green fluorescent protein) (30). Teniendo en cuenta que el VHC es esencialmente hepatotrópico, el sistema de expresión de la proteína core del VHC en células hepáticas se ha propuesto como un modelo apropiado para el estudio de las propiedades de esta proteína viral $(25,30)$.

En este estudio se planteó la hipótesis de que la expresión heteróloga de la proteína core del VHC en células HepG2 se asocia con cambios en la expresión del ARN; por lo tanto, el objetivo fue obtener y comparar de manera simultánea los perfiles del ARNm en células HepG2 transducidas con partículas recombinantes (rSFV) para la proteína core del VHC, para la proteína verde fluorescente (rSFV-GFP) y en células sin transducir. En este trabajo se muestran diferencias en los perfiles de expresión del ARNm en células HepG2 con expresión transitoria de las proteínas heterólogas y se identifica uno de los genes endógenos expresados en la células hepáticas trasducidas con rSFV-Core.

\section{Materiales y métodos}

\section{Células}

Se cultivaron células HepG2, gentilmente proporcionadas por Sócrates Herrera (Universidad del Valle, Colombia), en RPMI-1640 (Gibco Life Technologies, Estados Unidos), con suplemento de $1 \%$ de penicilina/estreptomicina, $25 \mathrm{mM}$ de Hepes, $1 \%$ de L-glutamina y $10 \%$ de suero fetal bovino, SFB, (Gibco Life Technologies, Estados Unidos), a $37^{\circ} \mathrm{C}$ en una atmósfera al $5 \%$ de $\mathrm{CO}_{2}$ (30).

\section{Partículas virales recombinantes y transducción de células HepG2}

Se utilizaron partículas virales recombinantes obtenidas previamente por Henao y col (30) mediante cotransfección de los ARN mensajeros transcritos in vitro de pSFV1-Core o pSFV-GFP y pSFV-helper en células BHK21 (30). Para la transducción de células HepG2 $\left(1,5 \times 10^{7}\right)$ se utilizaron las partículas rSFV-Core o rSFV-GFP a una multiplicidad de infección (MOI) de 0,5 y se incubaron a $37^{\circ} \mathrm{C}$ en una atmósfera al $5 \%$ de $\mathrm{CO}_{2}$, en medio RPMI con $10 \%$ de SBF durante 24 horas (30). Como control se utilizaron células tratadas en idénticas condiciones, pero en ausencia de partículas recombinantes. La confirmación de la expresión de la proteína verde fluorescente, GFP, y de la proteína core en células HepG2 se realizó por Western blot, inmunofluorescencia indirecta y análisis de citometría de flujo, respectivamente, como se describió previamente (30).

\section{Presentación diferencial de ARNm}

Después de demostrar la expresión de las proteínas en las células hepáticas se realizó la extracción de ARN total (31) a partir de 1,5 x 107 células transducidas con rSFV-Core o con rSFVGFP y de células control no transducidas; se utilizó el reactivo TRIZOL (Gibco Life Technologies, Estados Unidos) de acuerdo con las instrucciones del fabricante. Para eliminar el ADN genómico contaminante, el ARN total $(50 \mu \mathrm{g})$ fue tratado con la enzima ADNasa I (Fermentas, Estados Unidos) a una concentración final de 10 unidades/ mg de ARN e incubado por una hora a $37^{\circ} \mathrm{C}$. El ARN total libre de ADN se recuperó mediante extracción con fenol:cloroformo 3:1, pH 4,8 (Sigma, Estados Unidos). La fase acuosa se precipitó con acetato de sodio $(0,1 \mathrm{vol}, 3 \mathrm{M})$ y etanol absoluto (2,2 vol), el ARN se lavó con etanol al $75 \%$ y se resuspendió en agua libre de ARNasa (32).

La cantidad del ARN total se estimó por medio de espectrofotometría a $260 \mathrm{~nm}$ y la calidad por la relación $260 / 280(1,8$ a 2,0$)$ y por la integridad del ARN, evaluada por electroforesis en gel de 
agarosa $(1,2 \%)$ en buffer Tris acetato EDTA (TAE), $1 \mathrm{X}$.

La presentación diferencial de ARNm se realizó según el protocolo descrito previamente por Gómez y col (33). En forma resumida, el ARN total (5 ug) obtenido de células HepG2 sin transducir y transducidas con rSFV-Core o rSFVGFP se transcribió con la transcriptasa reversa Super Script II (Invitrogen, Estados Unidos) con el iniciador T12MG descrito por Liang y Pardee (34). Los ADNc correspondientes fueron amplificados por PCR utilizando el mismo iniciador T12MG (TTTTTTTTTTTMG) y otro iniciador arbitrario, AP-3 (AGGCGAACA) (Gene Hunter, Estados Unidos) en presencia de $\alpha^{32} \mathrm{P}-\mathrm{dCTP}$ (ICN, Estados Unidos). Después de la PCR, los productos de amplificación fueron separados en un gel de poliacrilamida (6\%) en condiciones no denaturantes y a partir del gel seco; la autoradiografía se obtuvo por calor y vacío (Hyperfilm, Amersham, Inglaterra).

Las autorradiografías se analizaron por comparación de la localización y de las intensidades de las bandas como se explica en la sección de análisis de datos. Las bandas que presentaron diferencias en su intensidad se seleccionaron y se recuperaron del gel de poliacrilamida por elución en agua . Dos microlitros del producto eluído se reamplificaron, utilizando el mismo par de iniciadores descritos arriba. Los productos amplificados se separaron en un gel de agarosa $(1,8 \%)$ fueron purificados con el sistema de purificación de productos de PCR (GFX, Amersham, Estados Unidos) y clonados en el vector pGEM-T-Easy (Promega, Estados Unidos) como se describió previamente (33).

A partir de $500 \mathrm{ng}$ de ADN plasmídico recombinante, extraído por el método de lisis alcalina (35), se realizó la secuenciación utilizando el método de Sanger (36) con el sistema de secuenciación Big Dye Terminador (Perkin Elmer, Estados Unidos) y el secuenciador automático Gene Analyzer (ABI Prism 310, Applied Biosystem, Estados Unidos). Las secuencias obtenidas se analizaron con el Software Vector NTI Suite (Informax) y se compararon con las secuencias disponibles en las bases de datos de dominio público (GenBank, EMBL) vía BLAST (37).

\section{Análisis de datos}

La expresión de los genes de los tres grupos experimentales se analizó comparando los niveles de expresión relativos, en los que cada banda representa los genes diferencialmente expresados producto del differential display. Las autorradiografías fueron digitalizadas y mediante procesamiento y análisis de las imágenes digitales se cuantificaron las intensidades relativas de cada una de las bandas por medio del sistema de análisis y documentación de electroforesis EDAS 290 (Eastman, Kodak, Inglaterra) y el software de análisis de imágenes Kodak 1D 3.5. Cada banda se cuantificó en una escala de niveles de grises en la que el nivel 0 representaba la banda más intensa u oscura y el nivel de 256 representaba la banda menos intensa o clara.

Con el fin de eliminar los factores experimentales que pudieran influir en los niveles relativos de las intensidades de los genes expresados (por ejemplo posibles diferencias en la marcación en la reacción de PCR y en las eficiencias de detección por diferencias en la cantidad de ARN inicial y background) los valores de intensidad de cada banda fueron normalizados restándoles el valor del background y debido a que la masa total de productos de ADNc sembrado en el gel de poliacrilamida fue igual $(2 \mu \mathrm{l}$ del producto de la reacción con la misma actividad específica $\alpha-{ }^{32} \mathrm{PdCTP} 3000 \mathrm{Ci} / \mathrm{mmol}$ ) en los diferentes grupos experimentales, los niveles relativos de intensidad se compararon usando la expresión $\left[\log _{2}(T / N T)\right]$ en donde $T$ es el promedio \pm desviación estándar de las intensidades de las bandas detectadas en la autorradiografía del grupo transducido (rSFV-GFP o rSFV-Core) y NT es el promedio \pm desviación estándar de las intensidades de las bandas detectadas en la autorradiografía del grupo de células no transducidas (34).

Para identificar genes diferencialmente expresados se establecieron como punto de comparación las bandas obtenidas de las células no transducidas, y para saber si el promedio de las intensidades de las bandas diferían entre los grupos, se realizó análisis de varianza y la prueba de Fisher (38). El 
valor de $p<0,05$ se consideró estadísticamente significativo.

\section{Resultados}

A las 24 horas de la transducción con las partículas recombinantes se observó que las células HepG2 no transducidas (Sin rSRV, figura 1A) tenían una morfología fibroblastoide y se adherían a la matriz extracelular; en contraste, las células HepG2 transducidas con rSFV-GFP y rSVF-Core presentaron una morfología redondeada y se desprendían de la matriz extracelular (figura 1B y C). Este efecto citopático fue más evidente en las células transducidas con rSFV-Core (figura 1C) que en las células transducidas con rSFV-GFP (figura 1B), lo cual sugirió que, además del efecto citopático inducido

A

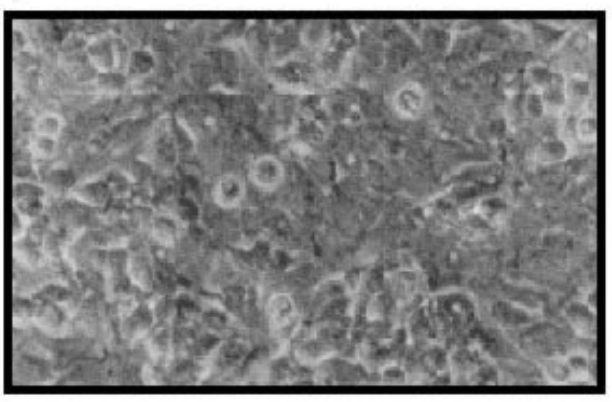

C

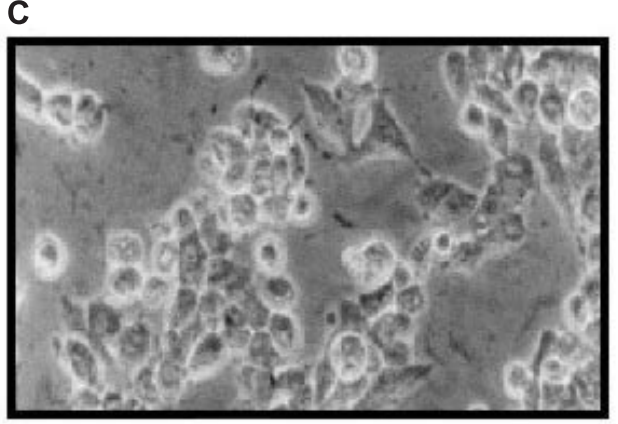

por el vector viral, la proteína core del VHC podría tener un efecto tóxico.

Mediante el análisis de Western blot se observó la presencia de una banda de $21 \mathrm{kDa}$ correspondiente a la proteína core en células transducidas con rSFV-Core y su ausencia en las no transducidas (figura 1D); por análisis de citometría de flujo se detectó la presencia de GFP en células transducidas con rSFV-GFP (dato no mostrado), como fue reportado por Henao y col (30).

Luego de varios ensayos con diferentes tiempos de transducción $(24,48$ y $72 \mathrm{~h}$, datos no mostrados), el ARN de las células HepG2 se extrajo a las 24 horas de la transducción, tiempo que garantizó la expresión de la proteína

B

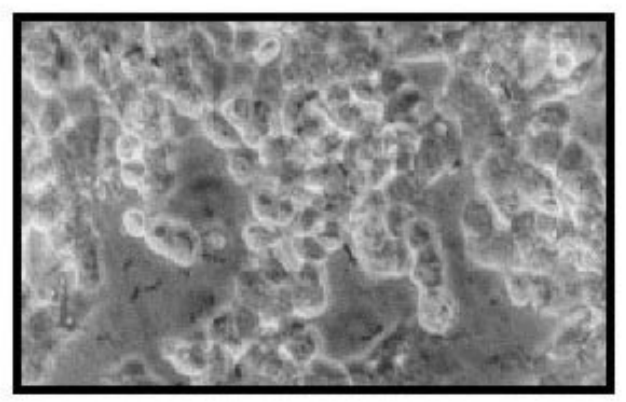

D

Sin rSFV rSFV-Core

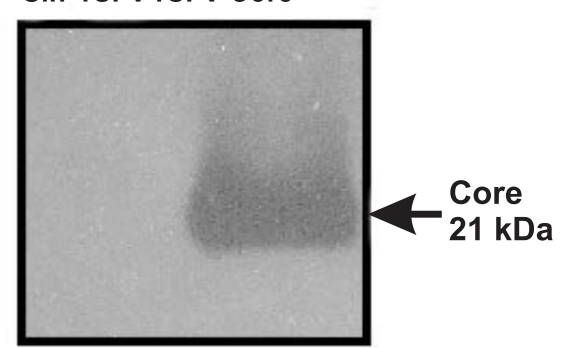

Figura 1. Efecto de la transducción con partículas recombinantes rSFV-Core y rSFV-GFP en células HepG2 y expresión de la proteína core del VHC. A, B, C. Fotografías de células de hepatocarcinoma HepG2 sin transducir (A, Sin rSFV) y transducidas con el sistema de expresión SFV construido para expresar las proteínas heterólogas GFP (B, rSFV-GFP) y core del VHC (C, rSFV-Core); estas células presentan una morfología más redondeada y se desprenden de la matriz extracelular. D. Fotografía de Western blot (panel inferior derecho) que muestra la expresión de la proteína core (21 kDa) detectada por quimioluminiscencia (ECL western blot, Amersham) de proteínas extraídas de células HepG2 sin transducir (Sin rSFV) y transducidas (rSFV-Core) a un MOI de 0,5 después de haber sido fraccionadas en geles de poliacrilamida (10\%) y transferidas a membrana de PVDF (Henao, 2004). 
heteróloga core, con el menor efecto del vector SFV sobre la viabilidad de las células (figura 1). Después de usar dos iniciadores arbitrarios en los ensayos de presentación diferencial de ARNm observamos que su perfil de expresión entre células HepG2 transducidas con rSFV-Core (figura $2 \mathrm{~A}$, carril 3) no presentó mucha diferencia comparado con el perfil de expresión obtenido de las células transducidas con rSFV-GFP (figura 2A, carril 2) y no transducidas (figura $2 \mathrm{~A}$, carril 1). En los tres grupos experimentales (células HepG2 no transducidas, transducidas con rSFV-GFP y rSFV-Core) se detectaron 42, 43 y 44 bandas, respectivamente.

Dentro de cada uno de los grupos de genes expresados se observaron distribuciones de intensidades de bandas individuales que variaron entre 85 (bandas más oscuras) y 228 (bandas más

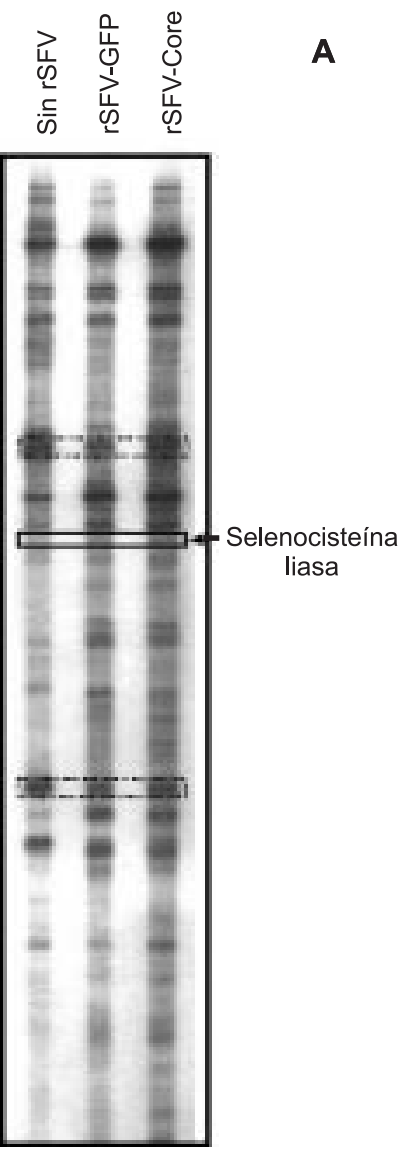

B

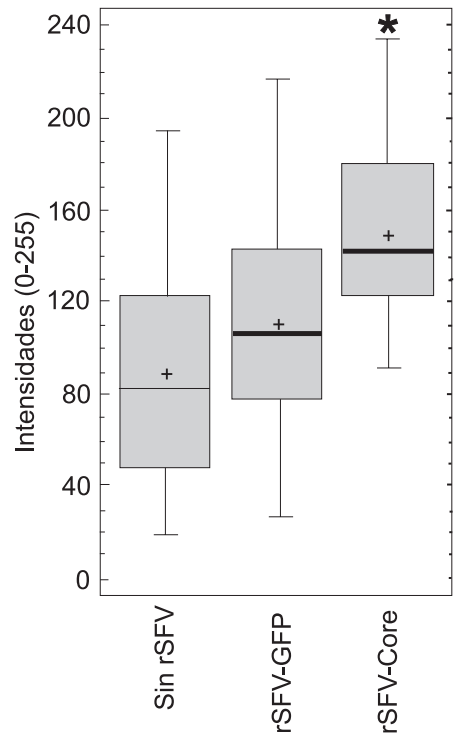

Figura 2. DD-RT-PCR y genes diferencialmente presentados. A. Autorradiografía que muestra perfiles de expresión y genes diferencialmente expresados obtenidos por la técnica de differential display (DD-RT-PCR) de células HepG2 sin transducir (Sin rSFV) y transducidas con el sistema de expresión SFV expresando las proteínas heterólogas GFP (rSFVGFP) y core (rSFV-Core). Se observa la presencia de bandas con migración e intensidad similar entre los grupos experimentales (cuadros en línea punteada) que sirvieron como control interno. Además, con la flecha se señala uno de los ADNc diferencialmente expresado con mayor intensidad en el grupo rSFV-Core y con menor intensidad en los otros dos grupos experimentales (cuadro línea continua). Este cADN fue clonado, secuenciado e identificado como selenocisteína liasa. B. Gráfica de cajas que muestra las distribuciones de las intensidades de las bandas de los perfiles de expresión obtenidos en cada grupo celular con rSFV-Core, rSFV-GFP y sin rSFV. La línea en el centro de cada caja representa el valor de la mediana de la distribución y los extremos superior e inferior de las cajas son los cuartiles superior (25) e inferior (75), respectivamente. Las líneas por fuera de las cajas muestran los rangos. Para comparar si las intensidades de las bandas diferían entre los grupos experimentales, se realizó análisis de varianza y la prueba de Fisher (como se indicó en materiales y métodos). El asterisco indica diferencia significativa $(p<0,05, \mathrm{n}=44)$. 
claras) niveles de grises en el grupo transducido con rSFV-Core, entre 11 y 190 niveles de grises en el grupo no transducido y entre 17 y 206 niveles de grises en el grupo transducido con rSFV-GFP. Las bandas se distribuyeron homogéneamente en cada uno de los carriles y la mayoría de estos $A D N c$, que representan los diferentes genes expresados, presentaron migraciones relativamente semejantes (figura 2A). Sin embargo, la diferencia se detectó por la intensidad de algunas bandas como se muestra en la figura 2. Las bandas cuya intensidad era mayor o menor que la del grupo no transducido se consideraron como aumentadas o disminuidas en su expresión, respectivamente. Este resultado fue reproducible en tres ensayos diferentes de trascripción reversa con el primer T12MG, seguida de PCR con el mismo iniciador T12MG y el iniciador arbitrario (AP-3).

Después de normalizar las intensidades relativas de cada banda, el análisis comparativo de los niveles de intensidad y la distribución de las bandas de cada carril revelaron que las células transducidas con rSFV-Core mostraron niveles de expresión relativos diferentes comparados con los niveles de expresión de células sin transducir y transducidas con rSFV-GFP (figura 2B). Por ejemplo, se observaron diferencias significativas y reproducibles en los niveles de expresión relativos de $A R N m$ en las células HepG2 transducidas con rSFV-Core (promedio $143 \pm 37$, $\mathrm{n}=44, p<0,05)$ con respecto a los promedios del grupo no transducido $(83 \pm 51, n=42)$ y del grupo transducido con rSFV-GFP $(102 \pm 45, n=42)$. Sin embargo, la comparación de los promedios entre estos dos grupos no mostró diferencias estadísticamente significativas ( $n=42, p>0,05)$. Estos hallazgos indican que los perfiles de expresión pueden identificarse con base en la comparación de la migración de las bandas y en el promedio de intensidades relativas de los genes expresados.

El análisis de la presencia o ausencia de bandas $y$ de las intensidades relativas en las autorradiografías (recuadros de la figura 2A) permitió la detección de un fragmento ADNc de 258 pares de bases (figura $2 A$, señalado con la flecha) expresado diferencialmente en el grupo
rSFV-Core y que no se observó en las células no transducidas ni en las transducidas con rSFV-GFP (recuadro línea punteada, figura 2A). Este ADNc se purificó y se clonó como se describe en materiales y métodos (datos no mostrados), y la caracterización de este fragmento se realizó por medio del análisis de su secuencia en las dos direcciones 5'-3‘y 3'-5“ (figura 3). La búsqueda de homología con otras secuencias reportadas en las bases de datos disponibles (GenBank, EMBL) vía BLAST reveló una identidad del $98 \%$ con secuencias de ADNc reportadas, las cuales codifican para la enzima selenocisteína liasa humana (número de acceso al GenBank BC000586.2), sugiriendo que las células HepG2 transducidas con rSFV-Core expresan este gen (37). El análisis de la secuencia que encontramos (número de acceso al GenBank AK002119.1) mostró un enriquecimiento en A (27\%) y T (29\%) y la presencia de las secuencias consensos UUUTUU (39), consideradas como señal de poliadenilación, y de la secuencia UAAAU, propia de elementos ricos en $A U$ (figura 3B, señaladas en color rojo). Además, observamos diferencias en 4 de los 217 nucleótidos en el alineamiento realizado con la secuencia de $A D N c$ humano (figura 3B, letras verdes). Estas características de secuencia son comunes en los extremos 3' de los ARNm que codifican proteínas y regulan su estabilidad (39).

\section{Discusión}

Los resultados presentados en este trabajo ilustran el potencial del sistema de expresión heteróloga basado en el replicón del SFV y de la presentación diferencial de $\mathrm{mARN}$ en el estudio de la proteína core del VHC expresado en células HepG2, así como en el análisis de la expresión diferencial de genes en presencia o ausencia de la proteína viral. Esta aproximación experimental permitió la detección y la clonación molecular de un fragmento del ADNc que codifica para la selenocisteína liasa, uno de los ADNc expresados diferencialmente en células HepG2 transducidas con rSFV-Core, con respecto a las células sin transducir y a las transducidas con rSFV-GFP. Este es el primer reporte de la asociación entre la expresión de este gen en células HepG2 y la proteína core del virus de la hepatitis C. Las 

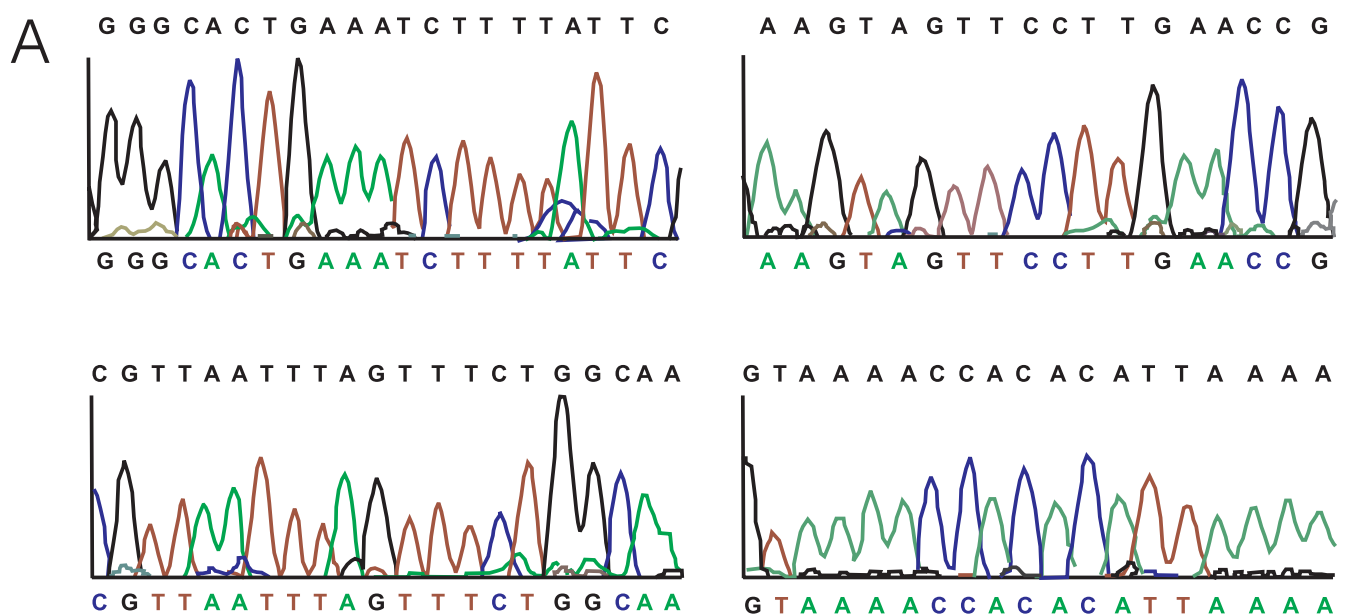

C G T T A A T T TA G T T T C T G G CA A

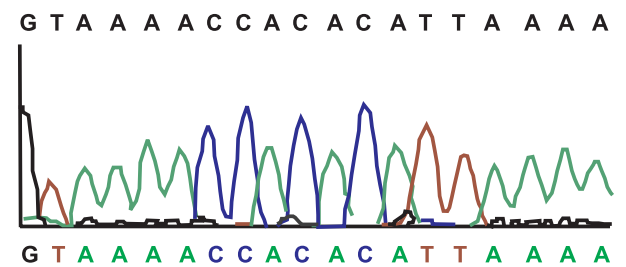

G T

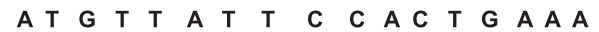
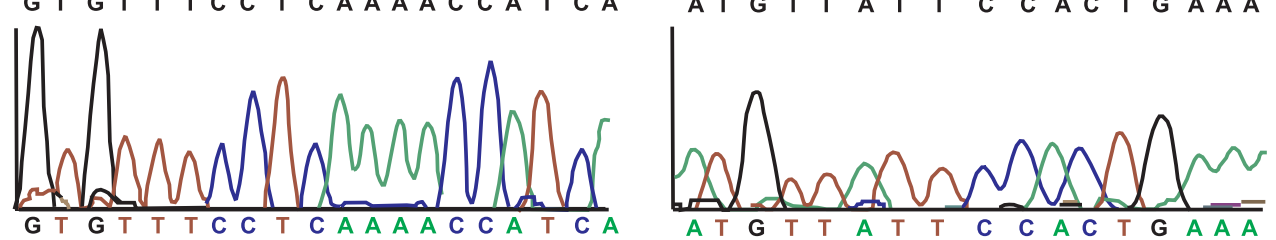

B

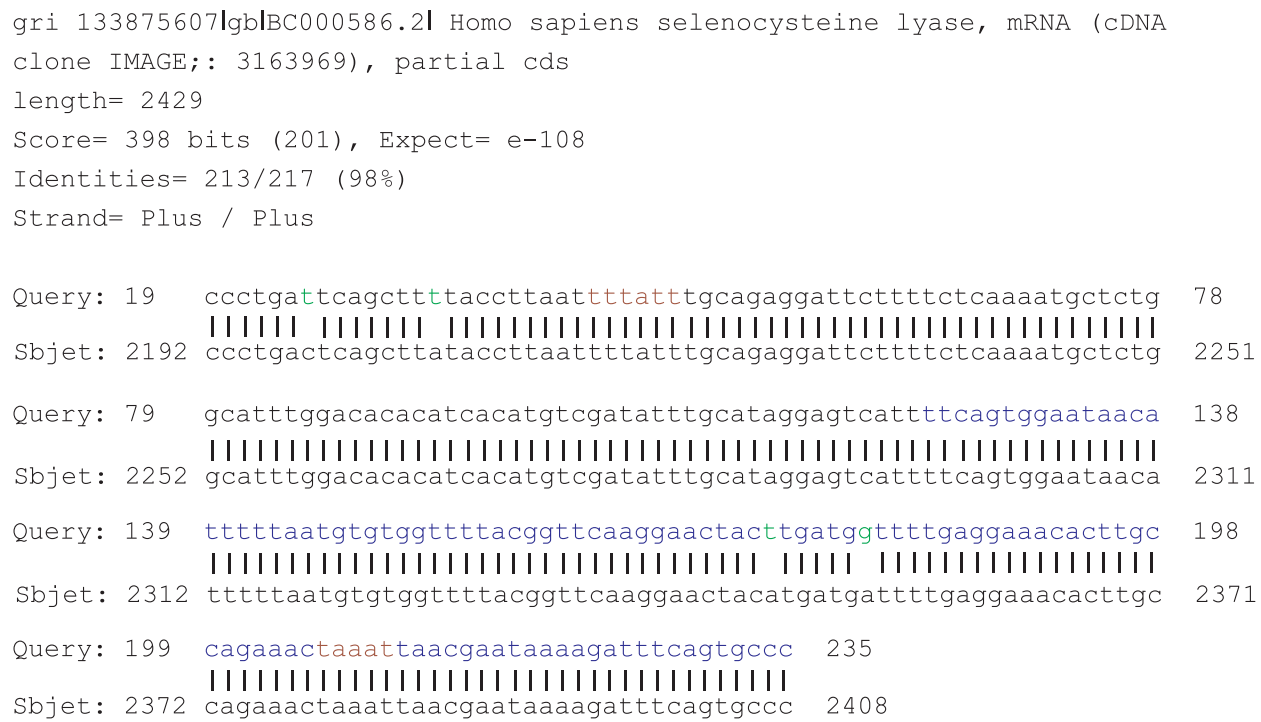

Figura 3. Secuencia del ADNc presentado diferencialmente y comparación con secuencias del GenBank vía Blast. A. En la figura se ilustra parte del electrofluorograma obtenido como resultado de la secuenciación del fragmento de ADNc purificado y clonado como se describe en materiales y métodos. B. Comparación de la secuencia obtenida, que resultó tener $98 \%$ de identidad con el extremo 3' del ARNm del gen de la selenocisteína liasa humana. Las secuencias consenso señaladas en letras rojas fueron encontradas con el Software Vector NTI Suite. 
características y actividades conocidas de la selenocisteína liasa (40-42) y el análisis de factores promotores que intervienen en la hepatocarcinogénesis (40-45) nos permiten proponer una posible participación de esta proteína en el carcinoma hepatocelular.

La diferencia observada en el efecto citopático de los cultivos celulares transducidos con rSFVCore comparado con el observado en el caso de rSFV-GFP podría deberse a un efecto de la proteína core en la regulación de la apoptosis o, alternativamente, a efectos citopáticos y tumoricidas del vector de expresión SFV $(28,46-$ 48). La interacción de core con el dominio citoplasmático de dos miembros de la familia de receptores del factor de necrosis tumoral (TNF), TNFR-1 y CD95, se ha demostrado in vitro (4954). Esta interacción parece estar implicada en la apoptosis observada en las líneas de células hepáticas como HepG2 y Hut78 con expresión transitoria de la proteína core (55-57). Por lo tanto, se requieren estudios adicionales, incluidos estudios de expresión de la proteína core utilizando otro sistema de expresión distinto al SFV, y ensayos que evalúen directamente las propiedades proapoptóticas de la proteína core, algunos de los cuales están en curso.

Una aproximación para empezar a entender los efectos de la expresión de proteínas del virus de la hepatitis $C$ en células hepáticas es identificar cambios en la expresión de genes en la presencia o ausencia de la proteína de interés $(24,58,59)$. En este trabajo observamos perfiles de expresión de ARNm semejantes en células HepG2 sin transducir y expresando la proteína GFP. Sin embargo, en células que expresan la proteína core, el perfil de expresión de los ARNm cambia y uno de los genes expresados diferencialmente en estas células es el gen que codifica para la selenocisteína liasa, SLC. Para demostrar la relación causal entre la expresión diferencial de este gen y la proteína core del VHC es necesario realizar estudios de expresión de este gen por Northern blot o RT-PCR cuantitativa en el sistema descrito en este estudio y compararlos con las condiciones durante la infección natural, lo cual podría realizarse con el reciente establecimiento de dos promisorios modelos de replicación in vitro del VHC $(48,51,52,58,60)$.

La detección e identificación de la expresión del gen SCL en el hepatocarcinoma humano HepG2 permite sugerir un papel de este gen en la promoción del carcinoma hepatocelular que no se ha propuesto previamente (45). El gen SLC se expresa normalmente en varios tejidos, preferencialmente en hígado, riñón y testículos $(40,41)$, y codifica para la enzima que cataliza la formación de L-alanina y selenio elemental a partir de la L-selenocisteína, una molécula que cuando se encuentra libre es tóxica y al acumularse puede llegar a ser letal $(40,41)$. La enzima, en conjunto con la selenofosfato sintetasa, también participa en la biosíntesis de selenoproteínas y de metil selenocisteína, moléculas importantes en la homeostasis del estado de óxido-reducción celular y en la síntesis de derivados de cisteína, moléculas que tienen la propiedad de tener acciones de quimioprevención contra el cáncer $(44,61)$. Estos efectos y actividades, así como la relación entre carcinoma hepatocelular, incremento en la producción de ROS y estrés oxidativo (45), y el resultado de nuestro trabajo, permiten plantear por primera vez una posible asociación entre la expresión de la selenocisteína liasa y el carcinoma hepático. Proponemos que la expresión de la selenocisteína liasa está finamente regulada, y que su alteración puede estar involucrada en el cáncer de dos maneras; cuando aumenta su expresión o actividad, la acción detoxificadora y de defensa antioxidante incrementaría la viabilidad y longevidad celular, facilitando o promoviendo la acción de agentes tumorales $(44,45)$. Alternativamente, cuando su expresión o actividad está disminuida, conduciría a una menor producción de selenoproteínas y derivados, conduciendo a una menor protección contra especies reactivas de oxígeno, ROS, que pueden dañar constituyentes celulares, oxidar el ADN y modificar proteínas que en conjunto promueven la carcinogénesis $(44,45,61,62)$. No obstante, estas hipótesis requieren ser investigadas específicamente en el cáncer hepático.

En conclusión, los resultados de este trabajo confirman que la expresión de la proteína core del virus de la hepatitis $C$ se asocia con cambios 
en la expresión de ARN mensajeros específicos, incluyendo al gen SLCque puede estar involucrado en la fisiopatología del carcinoma hepatocelular.

\section{Agradecimientos}

Los plásmidos pSFV-Core y pSFV-GFP fueron construidos durante los estudios doctorales de María Cristina Navas bajo la asesoría de Françoise Stoll-Keller del Institut de Virologie, Université Louis Pasteur en Estrasburgo, Francia, y de Jovan Pavlovic del Institute of Virology, University of Zurich, Zurich, Suiza. Los autores agradecen al Instituto Colombiano para el Desarrollo de la Ciencia y la Tecnología "Francisco José de Caldas", COLCIENCIAS, al Comité para el Desarrollo de la Investigación de la Universidad de Antioquia (CODI) y al Instituto Nacional de Salud.

\section{Conflicto de intereses}

Los autores declaran no tener vinculación laboral con ningún laboratorio farmacéutico o empresa interesada en obtener resultados positivos o negativos de la investigación.

\section{Financiación}

Este trabajo se realizó con el apoyo financiero del Instituto Colombiano para el Desarrollo de la Ciencia y la Tecnología "Francisco José de Caldas", COLCIENCIAS (Proyectos 1115-0410228 y 2104-12-11563), el Comité para el Desarrollo de la Investigación de la Universidad de Antioquia (CODI) y el Instituto Nacional de Salud.

\section{Referencias}

1. Choo QL, Kuo G, Weiner AJ, Overby LR, Bradley DW, Houghton M. Isolation of a cDNA clone derived from a blood-borne non-A, non-B viral hepatitis genome. Science 1989;244:359-62.

2. Alberti A, Benvegnu ML. Management of hepatitis C. J Hepatol 2003;38(Suppl. 1):S104-18.

3. World Health Organization. Hepatitis C-Global prevalence (update). Wkly Epidemiol Rec 2000;75:18-9.

4. Penin F, Dubuisson J, Rey FA, Moradpour D, Pawlotsky JM. Structural biology of hepatitis $C$ virus. Hepatology 2004;39:5-19.

5. Santolini E, Migliaccio G, La Monica N. Biosynthesis and biochemical properties of the hepatitis $C$ virus core protein. J Virol 1994;68:3631-41.
6. Matsumoto M, Hwang SB, Jeng KS, Zhu N, Lai MM. Homotypic interaction and multimerization of hepatitis C virus core protein. Virology 1996;218:43-51.

7. McLauchlan J. Properties of the hepatitis $C$ virus core protein: a structural protein that modulates cellular processes. J Viral Hepat 2000;7:2-14.

8. Ray RB, Lagging LM, Meyer K, Steele R, Ray R. Transcriptional regulation of cellular and viral promoters by the hepatitis C virus core protein. Virus Res 1995; 37:209-20.

9. Lu W, Lo SY, Chen M, Wu K, Fung YK, Ou JH. Activation of p53 tumor suppressor by hepatitis $C$ virus core protein. Virology 1999; 264:134-41.

10. Ray RB, Steele R, Meyer K, Ray R. Hepatitis C virus core protein represses p21WAF1/Cip1/Sid1 promoter activity. Gene1998;208:331-6.

11. Ruggieri A, Harada T, Matsuura Y, Miyamura T. Sensitization to Fas-mediated apoptosis by hepatitis C virus core protein. Virology 1997;229:68-76.

12. Marusawa $\mathbf{H}$, Hijikata $\mathbf{M}$, Chiba $\mathbf{T}$, Shimotohno $\mathbf{K}$. Hepatitis $C$ virus core protein inhibits Fas and tumor necrosis factor alpha-mediated apoptosis via NFkappaB activation. J Virol 1999;73:4713-20.

13. Hahn CS, Cho YG, Kang BS, Lester IM, Hahn YS. The HCV core protein acts as a positive regulator of fas-mediated apoptosis in a human lymphoblastoid $T$ cell line. Virology 2000;276:127-37.

14. Ray RB, Laggin LM, Meyer K, Ray R. Hepatitis C Virus core protein cooperates with ras and transforms primary rat embryo fibroblasts to tumorigenic phenotype. J Virol 1996;70:4438-43.

15 Moriya K, Fujie H, Shintani Y, Yotsuyanagi H, Tsutsumi $\mathrm{T}$, Ishibashi $\mathrm{K}$, et al. The core protein of hepatitis $C$ virus induces hepatocellular carcinoma in transgenic mice. Nat Med 1998;4:1065-7.

16. Yoshida T, Hanada T, Tokuhisa T, Kosai K, Sata M, Kohara M, et al. Activation of STAT3 by the hepatitis C virus core protein leads to cellular transformation. J Exp Med $2002 ; 196: 641-53$.

17. Moriya K, Yotsuyanagi H, Shintani Y, Fujie H, Ishibashi K, Matsuura $\mathbf{Y}$, et al. Hepatitis $\mathrm{C}$ virus core protein induces hepatic steatosis in transgenic mice. J Gen Virol 1997;78:1527-31.

18. Barba G, Harper F, Harada T, Kohara M, Goulinet S, Matsuura $Y$, et al. Hepatitis $C$ virus core protein shows a cytoplasmic localization and associates to cellular lipid storage droplets. Proc Natl Acad Sci U S A 1997;94:1200-5.

19. Large MK, Kittlesen DJ, Hahn YS. Suppression of host immune response by the core protein of hepatitis C virus: possible implications for hepatitis $C$ virus persistence. J Immunol 1999;162:931-8.

20. Soguero C, Joo M, Chianese-Bullock KA, Nguyen DT, Tung K, Hahn YS. Hepatitis C virus core protein 
leads to immune suppression and liver damage in a transgenic murine model. J Virol 2002;76:9345-54.

21. Dolganiuc A, Kodys K, Kopasz A, Marshall C, Do T, Romics L Jr, et al. Hepatitis $C$ virus core and nonstructural protein 3 proteins induce pro- and antiinflammatory cytokines and inhibit dendritic cell differentiation. J Immunol 2003 1;170:5615-24.

22. Alisi A, Giambartolomei S, Cupelli F, Merlo P, Fontemaggi G, Spaziani A, et al. Physical and functional interaction between HCV core protein and the different p73 isoforms. Oncogene 2003;22:257380 .

23. Su AI, Pezacki JP, Wodicka L, Brideau AD, Supekova $\mathrm{L}$, Thimme R, et al. Genomic analysis of the host response to hepatitis $\mathrm{C}$ virus infection. Proc Natl Acad Sci USA 2002;99:15669-74.

24. Ohkawa K, Ishida H, Nakanishi F, Hosui A, Sato A, Ueda $\mathbf{K}$, et al. Changes in gene expression profile by $\mathrm{HCV}$ core protein in cultured liver cells: analysis by DNA array assay. Hepatol Res 2003;25:396-408.

25. Liu M, Zhang SL, Cheng J, Liu Y, Wang L, Shao Q, et al. Genes transactivated by hepatitis $C$ virus core protein, a microarray assay. World J Gastroenterol 2005 14;11:3351-6.

26. Schinazi RF, Ilan E, Black PL, Yao X, Dagan S. Cellbased and animal models for hepatitis $B$ and $C$ viruses. Antivir Chem Chemother 1999;10:99-114.

27. Sun BS, Pan J, Clayton MM, Liu J, Yan X, Matskevich AA, et al. Hepatitis $C$ virus replication in stably transfected HepG2 cells promotes hepatocellular growth and tumorigenesis. J Cell Physiol 2004;201:44758.

28. Lundstrom K, Schweitzer C, Richards JG, Ehrengruber M, Jenck F, Muhlhardt C. Semliki forest virus vectors for in vitro and in vivo applications. Gene Ther Mol Biol 1999;4:23-31.

29. Torresi J, Meanger J, Lambert P, Li F, Locarnini SA, Anderson DA. High level expression of the capsid protein of hepatitis $E$ virus in diverse eukaryotic cells using the Semliki Forest virus replicon. J Virol Methods 1997;69:81-91.

30. Henao LF, Yepes JO, Alvarez CM, Balcazar N, Navas MC. Expresión de la proteína verde fluorescente y proteína Core del virus de la hepatitis $C$ en la línea de hepatoma HepG2 mediante el sistema de expresión del Semliki Forest Virus. Act Biol 2004;26:23-9.

31. Chomczynski P. Solubilization in formamide protects RNA from degradation. Nucleic Acids Res 1992;20:3791-2.

32. Sambrook J, Fritsch EF, Maniatis T. Molecular Cloning. A Laboratory Manual. Second Edition. Cold Spring Harbor: Laboratory Press; 1989.

33. Gomez LA, Strasberg Rieber M, Rieber M. PCRmediated differential display and cloning of a melanocyte gene decreased in malignant melanoma and upregulated with sensitization to DNA damage. DNA Cell Biol 1996;15:423-7.

34. Liang P, Averboukh L, Keyomarsi K, Sager R, Pardee AB. Differential display of eukaryotic messenger RNA by means the polymerase chain reaction. Science 1992;257:967-71.

35. Birnboim HC. A rapid alkaline extraction method for the isolation of plasmid DNA. Methods Enzymol 1983;100:243-55.

36. Sanger F, Nicklen S, Coulson AR. DNA sequencing with chain-terminating inhibitors. Proc Natl Acad Sci USA $1977 ; 74: 5463-7$.

37. Altschul SF, Gish W. Local alignment statistics. Methods Enzymol 1996;266:460-80.

38. Cleveland WS. Visualizing data. New Jersey: Hobart Press. Murray Hill; 1993.

39. Bevilacqua A, Ceriani MC, Canti G, Asnaghi L, Gherzi $\mathbf{R}$, Brewer $\mathbf{G}$, et al. Bcl-2 protein is required for the adenine/uridine-rich element (ARE)-dependent degradation of its own messenger. J Biol Chem 2003;278:23451-9.

40. Esaki N, Nakamura T, Tanaka H, Sodag K. Selenocysteine lyase, a novel enzyme that specifically acts on selenocysteine. Mammalian distribution and purification and properties of pig liver enzyme. J Biol Chem 1982;257:4386-91.

41. Mihara H, Kurihara T, Watanabe T, Yoshimura T, Esaki N. cDNA cloning, purification and characterization of mouse liver selenocysteine lyase. Candidate for selenium delivery protein in selenoprotein synthesis. J Biol Chem 2000;275: 6195-200.

42. Ip C, Thompson HJ, Zhu Z, Ganther HE. In vitro and in vivo studies of methylseleninic acid: evidence that a monomethylated selenium metabolite is critical for cancer chemoprevention. Cancer Res 2000;60: 2882-6.

43. Kretz-Remy C, Arrigo AP. Gene expression and thiol redox state. Methods Enzymol 2002;348:200-15.

44. Mitsui A, Hamuro J, Nakamura H, Kondo $\mathbf{N}$, Hirabayashi Y, Ishizaki-Koizumi S, et al. Overexpression of human thioredoxin in transgenic mice controls oxidative stress and life span. Antioxid Redox Signal 2002;4:693-6.

45. Maeda S, Kamata H, Luo JL, Leffert H, Karin M. IKKB couples hepatocyte death to cytokine-driven compensatory proliferation that promotes chemical hepatocarcinogenesis. Cell 2005;121:977-90.

46. Lingor P, Schöll U, Bähr M, Kügler S. Functional applications of novel Semliki Forest virus vectors are limited by vector toxicity in cultures of primary neurons in vitro and in the substantia nigra in vivo. Exp Brain Res 2005;161:335-42. 
47. Ehrengruber MU, Lundstrom K, Schweitzer C, Heuss C, Schlesinger S, Gahwiler BH. Recombinant Semliki Forest virus and Sindbis virus efficiently infect neurons in hippocampal slice cultures. Proc Natl Acad Sci USA 1999;96:7041-6.

48. Atkins GJ, Sheahan BJ, Liljestrom P. The molecular pathogenesis of Semliki Forest virus: a model virus made useful? J Gen Virol 1999;80:2287-97.

49. Glasgow GM, McGee MM, Tarbatt CJ, Mooney DA, Sheahan BJ, Atkins GJ. The Semliki Forest virus vector induces p53-independent apoptosis. J Gen Virol 1998;79:2405-10.

50. Fujita T, Ishido S, Muramatsu S, Itoh M, Hotta H. Suppression of actinomycin D-induced apoptosis by the NS3 protein of hepatitis C virus. Biochem Biophys Res Commun 1996;229:825-31.

51. Lan KH, Sheu ML, Hwang SJ, Yen SH, Chen SY, Wu JC, et al. HCV NS5A interacts with p53 and inhibits p53-mediated apoptosis. Oncogene 2002;21:4801-11.

52. Meyer K, Basu A, Saito K, Ray RB, Ray R. Inhibition of hepatitis $C$ virus core protein expression in immortalized human hepatocytes induces cytochrome c-independent increase in Apaf- 1 and caspase- 9 activation for cell death. Virology 2005;336:198-207.

53. Liljestrom P, Garoff $\mathbf{H}$. A new generation of animal cell expression vectors based on the Semliki Forest virus replicon. Biotechnology 1991;9:1356-61.

54. Langhans $B$, Lechmann $\mathbf{M}$, Ihlenfeldt $\mathbf{H}$, Jung $\mathbf{G}$, Giers G, Schweitzer S, et al. A hepatitis $\mathrm{C}$ virus (HCV) core protein derived peptide inhibits HCV specific lymphocyte proliferation. Eur J Med Res 2000;5:115-20.

55. Basu A, Meyer K, Ray RB, Ray R. Hepatitis C virus core protein is necessary for the maintenance of immortalized human hepatocytes. Virology 2002;298:53-62.

56. Ray RB, Laggin LM, Meyer K, Ray R. Hepatitis C Virus core protein cooperates with ras and transforms primary rat embryo fibroblasts to tumorigenic phenotype. J Virol 1996;70:4438-43.

57. Moriya K, Fujie H, Shintani Y, Yotsuyanagi $\mathbf{H}$, Tsutsumi $\mathrm{T}$, Ishibashi $\mathrm{K}$, et al. The core protein of hepatitis $\mathrm{C}$ virus induces hepatocellular carcinoma in transgenic mice. Nat Med 1998;4:1065-7.

58. Rheme C, Ehrengruber MU, Grandgirard D. Alphaviral cytotoxicity and its implication in vector development. Exp Physiol 2004;90:45-52.

59. Tsuchihara K, Hijikata M, Fukuda K, Kuroki T, Yamamoto N, Shimotohno K. Hepatitis C virus core protein regulates cell growth and signal transduction pathway transmitting growth stimuli. Virology 1999;258:100-7.

60. Zhong J, Gastaminza P, Cheng G, Kapadia S, Kato T, Burton DR, et al. Robust hepatitis $C$ virus infection in vitro. Proc Nat Acad Sci USA 2005;102:9294-9.

61. Unni E, Koul D, Yung WK, Sinha R. Semethylselenocysteine inhibits phosphatidylinositol 3kinase activity of mouse mammary epithelial tumor cells in vitro. Breast Cancer Res 2005;7:699-707.

62. Chang J, Yang S, Cho Y, Hwang SB, Hahn YS, Sung YC. Hepatitis $\mathrm{C}$ virus core from two different genotypes has an oncogenic potential but is not sufficient for transforming primary rat embryo fibroblast in cooperation with the H-ras oncogene. J Virol 1998;72:3060-5 